\title{
O HIBRIDISMO TECNOLÓGICO DIGITAL NA CONFIGURAÇÃO DO ESPAÇO DIGITAL VIRTUAL DE CONVIVÊNCIA: FORMAÇÃO DO EDUCADOR
}

\author{
LUCIANA BACKES \\ Centro Universitário La Salle (Unilasalle), Canoas, Rio Grande do Sul
}

RESUMO: O artigo aborda a formação do educador por meio das tecnologias digitais emergentes. A pesquisa contempla dois aspectos: contexto do hibridismo tecnológico digital; configuração dos espaços digitais virtuais de convivência. A reflexão ocorreu nos cursos de formação inicial do educador, desenvolvidos no Brasil e na França, no contexto do hibridismo tecnológico digital composto por: Ambiente Virtual de Aprendizagem; Comunicador Instantâneo; Blog e Metaverso. Por meio da metodologia de Estudo de Caso, evidenciamos que o espaço digital virtual de convivência se configura quando: os seres humanos representam a sua percepção em espaços digitais virtuais; a partir da representação de cada ser humano se instaura a perturbação, pois o outro é legítimo; há a necessidade de compensar a perturbação configurando um espaço comum, numa perspectiva de coexistência e de emergência.

Palavras-chave: Espaço. Hibridismo tecnológico digital. Espaço digital virtual de convivência. Formação do educador.

INTRODUÇÃO'

O cotidiano dos seres humanos vem sendo configurado, cada vez mais, de forma complexa. Ou seja, segundo Morin (2011), estamos percebendo esse cotidiano não de maneira fragmentada, mas em seu contexto, 
considerando seus antecedentes e seu devenir, sua multidimensionalidade, suas contradições, suas complementaridades, suas antagonias, incertezas, incompletudes e ambiguidades. Atualmente, configuramos o viver e conviver com o outro de diferentes maneiras. Podemos morar na França, trabaIhar no Brasil e escrevermos artigos com pesquisadores italianos. Também podemos ver estudantes, de diferentes idades, em escolas da rede pública de ensino no Brasil, utilizando dispositivos móveis e sem fio. Assim, como podemos ver, muitos adolescentes de diferentes espaços sociais utilizam seus telefones móveis para a comunicação, a interação e a manifestação no ciberespaço.

O ciberespaço, conceituado por Lévy (2010), é um espaço de comunicação aberto pela interconexão mundial dos computadores e das memórias dos computadores. "É um computador cujo centro está em toda parte e a circunferência em lugar algum, um computador hipertextual, disperso, vivo, fervilhante, inacabado: o ciberespaço em si" (p. 45). No desenvolvimento e na socialização das tecnologias digitais - TD, num híbrido entre ser humano, técnica e máquina, emerge um modo diferente de ver, perceber e viver a realidade.

A realidade nunca foi pura segundo Latour (1991). Conforme Santos (2006), atualmente não é mais possível distinguir onde termina a obra da natureza e onde começa a obra do homem, ou ainda, indicar onde termina o técnico e onde começa o social. Portanto, o hibridismo consiste em misturar objetos de tal forma, que não podem ser explicados separadamente. $\mathrm{Na}$ compreensão de hibridismo, os seres humanos vêm utilizando as diferentes TD no seu cotidiano, compondo e recompondo o que podemos chamar de hibridismo tecnológico digital, Backes $(2011,2013)$.

Em algumas universidades brasileiras encontramos estudantes que utilizam mídias sociais para criarem grupo de discussão sobre o conteúdo desenvolvido em seus cursos, ao mesmo tempo em que utilizam os Ambientes Virtuais de Aprendizagem (AVA), aplicativos de comunicação instantânea, entre outras TD disponíveis para uso educativo ou não. Essa composição do hibridismo tecnológico digital é percebida nas universidades porque no cotidiano desses estudantes isso já acontece há mais tempo. 
Os seres humanos nos diferentes contextos, educativo, profissional, social, religioso, configuram espaços de convivência próprios e particulares, em congruência com o meio (tempo e espaço - relações e interações). Ao configurar esse espaço de convivência, conceituado por Maturana e Varela (2002), por meio de TD, emerge a construção do conceito de espaço digital virtual de convivência, Backes $(2011,2013)$.

No viver cotidiano, compartilhado com o outro, é configurado por meio de espaços geograficamente localizados em coexistência com os espaços de natureza digital virtual, sendo estes consideravelmente ampliados na perspectiva do hibridismo tecnológico digital. Como pensar essa convivência nos processos de ensinar e de aprender?

A formação humana, segundo Maturana e Rezepka (2008), consiste no desenvolvimento do ser humano enquanto cocriador de um espaço de convivência desejável. Ou seja, implica em: criar condições para que o ser humano possa crescer no autorrespeito e no respeito pelo outro, considerar as particularidades, identificações e ontogenia de cada participante, estabelecer relações de cooperação. Assim, o ser humano (estudante e educador) é autor do seu processo de aprendizagem e responsável pela construção do conhecimento, no coletivo.

A Educação na contemporaneidade implica em considerar os processos de ensinar e de aprender, nessa coexistência entre os espaços geograficamente localizados e os espaços digitais virtuais e compreender que as rápidas mudanças ocorrem de maneira determinante e determinada entre educação e TD. Ao mesmo tempo em que as TD propiciam transformações na educação, a educação provoca a criação de novas TD. Segundo Santos (2006, p. 39), "É assim que o espaço encontra a sua dinâmica e se transforma". Nesse movimento surge a tecnologia-conceito Espaço de Convivência Digital Virtual (ECODI) sistematizada por Schlemmer et al. (2006); Schlemmer (2008, 2009, 2010).

A partir dessas considerações, fundamentamos as reflexões desse artigo, desenvolvido no estágio pós-doutoral na Université Paris Descartes Sorbonne (Bolsa financiada pela Coordenação de Aperfeiçoamento de Pessoal de Nível Superior - CAPES - Processo 18024-12-2). A investigação ocorreu por 
meio da metodologia de estudo de caso, envolvendo três processos de formação de educadores: dois cursos desenvolvidos no Brasil (2005-2006) e um curso na França (2011), essa pesquisa é de natureza qualitativa. Os processos formativos dos educadores se desenvolveram no contexto do hibridismo tecnológico digital e por meio de práticas-pedagógicas problematizadoras: Metodologia de projetos de aprendizagem baseados em problemas, adaptado ao ensino superior (SCHLEMMER, 2001, 2002), e Metodologia pedagógica de estudo de caso (BACKES, 2011; 2012).

\section{As Tecnologias Digitais no contexto do Hibridismo TeCnológico Digital}

As TD são hardwares e softwares como: ambiente virtual de aprendizagem, ambiente em realidade virtual, metaverso (mundo digital virtual em 3D-MDV3D), comunicador instantâneo, jogo, simulador, weblog, wiki, correio eletrônico, agente comunicativo, dentre outros. Assim como peopleware, que podem se organizar em comunidade virtual de aprendizagem, de prática e de relacionamento e/ou redes sociais. As TD podem ser compreendidas como ciberespaços, em complemento a Lévy (2010), citamos Lemos (2007, p.74)

[...] o ciberespaço não é só um espaço de comutação. Exemplos pululam neste sentido: chats, muds, fóruns newsgroups. Todos de conteúdos os mais diversos (acadêmico, erótico, revolucionário, marginal, político ou de lazer). 0 ciberespaço não é o deserto do real, assim como não é o fim da comunicação ou do social. Da mesma forma, os vírus de computador, como também as piratarias dos hackers, são expressões fortes dessa improvisação tecno-social.

No entanto, no contexto dessa pesquisa, compreendemos as TD como espaço digital virtual. Para tanto, precisamos retomar o conceito de espaço (SANTOS, 1980) e de digital e virtual (LÉVY, 2010).

O espaço pode ser entendido como uma configuração que se faz nas relações entre os seres vivos, por meio de: representações territoriais (natureza e matéria) e sociais (passado, presente e futuro); estrutura do momento atual vivido (processos e funções pertencentes ao nosso espaço); campo de força de ações (portanto desiguais).

[...] se define como um conjunto de formas representativas de relações sociais do passado e do presente e por uma estrutura representada por relações 
sociais que estão acontecendo diante dos nossos olhos e que se manifestam através de processos e funções. O espaço é, então, um verdadeiro campo de forças cuja aceleração é desigual. Daí porque a evolução espacial não se faz de forma idêntica em todos os lugares. (SANTOS, 1980, p.122)

O espaço é uma configuração da convivência entre os seres vivos e não uma configuração territorial. Conforme Santos (2006, p.38) “A configuração territorial não é o espaço, já que sua realidade vem de sua materialidade, enquanto o espaço reúne a materialidade e a vida que a anima".

Segundo Lévy (2010), o digital consiste na possibilidade de traduzir as informações em números, para que essas possam ser armazenadas, transmitidas e copiadas, assim como retraduzidas. Então um espaço digital seria um espaço onde as relações entre os seres vivos, atravessadas por toda complexidade, são traduzidas em números a fim de serem retraduzidas, ressignificadas para espaços de diferentes naturezas.

A palavra virtual, conforme Lévy (2010), contempla três conceitos diferentes. Um relacionado ao técnico, com origem na informática; outro ao uso corrente da linguagem que remete ao irreal; e um terceiro, com origem filosófica. Na filosofia, o virtual é o que existe em potência e não em ato, assim o virtual está antes da concretização efetiva (a limonada está virtualmente presente no limão). Portanto, 'É virtual toda entidade 'desterritorializada', capaz de gerar diversas manifestações concretas em diferentes momentos e locais determinados, sem, contudo estar ela mesma presa a um lugar ou tempo em particular" (LÉVY, 2010, p.49).

O espaço digital virtual é a configuração das relações estabelecidas por meio de TD. Assim, os espaços digitais virtuais se configuram por meio das TD que possibilitam a ação, relação, interação e compartilhamento das representações dos seres humanos; permitem criar espaços próprios e particulares de cada grupo social (pois os seres humanos estão em congruência com o meio); oferecem recursos que potencializam a coordenação das coordenações das ações (o ser humano compreende a ação do outro e atribui significado).

Então, a configuração do espaço digital virtual ocorre nas ações indissociáveis, solidárias e cooperativas, por meio de diferentes TD. Na medida em que novas TD são criadas e incorporadas ao cotidiano, os seres humanos 
atribuem outros e novos significados a elas. Dessa forma, há uma maior congruência entre o ser humano e o espaço digital virtual (TD), propiciando novos agrupamentos e integrações tecnológicas, assim como articulações, num hibridismo tecnológico digital.

O conceito do hibridismo tecnológico digital é criado no contexto das pesquisas desenvolvidas no Grupo de Pesquisa Educação Digital UNISINOS/CNPq, e encontra-se em construção, reflexão, amadurecimento e sistematização. Em nossas reflexões, a origem do conceito de hibridismo está na biologia (CANCLINI, 2006 apud FRANCK, 2012), cujo significado consiste no cruzamento de diferentes espécies. A palavra hibridismo unida aos adjetivos tecnológico e digital, segundo Backes (2011), resulta num conjunto de TD coerente (que no cruzamento pode ser diferente e contraditório) de possibilidades de realização da ação humana num espaço digital virtual.

O cruzamento, a integração e a articulação entre as TD, ocorrem na medida em que os seres humanos se apropriam, elaboram ou mobilizam os instrumentos (TD) em suas ações e interações. Portanto, o hibridismo tecnológico digital é criado e recriado a partir do significado atribuído durante a ação, ou seja, no viver e conviver entre os seres humanos em congruência com o espaço.

Nesse contexto do hibridismo, os seres humanos constituem o viver com o outro, também em espaços digitais virtuais, assim, configurando os espaços digitais virtuais de convivência. A configuração dos espaços digitais virtuais de convivência pode ser potencializada ainda mais, no hibridismo tecnológico digital.

A configuração do espaço digital virtual de convivência no contexto do hibridismo tecnológico digital possibilitou a emersão da tecnologia-conceito ECODI. Os ECODI consistem num hibridismo tecnológico digital onde: o fluxo de interação e comunicação, entre os seres humanos, ocorre de maneira textual, oral, gestual e/ou gráfica; as TD não são entendidas uma sem a outra, elas não são vistas separadamente. Para Backes (2011), cada ECODI é composto por um determinado hibridismo tecnológico digital, considerando a congruência dos participantes com as TD, portanto, a cada situação, o ECODI 
se recria. De acordo com Schlemmer et al. (2006, p. 8); Schlemmer (2008, p. 24), Schlemmer (2009, p. 143), Schlemmer (2010, p. 165) um ECODI compreende:

- diferentes TD integradas tais como: AVA, MDV3D, tecnologias da Web 2.0, agentes comunicativos ( $\mathrm{AC}$ - criados e programados para a interação), dentre outros, que favoreçam diferentes formas de comunicação (textual, oral, gráfica e gestual);

- fluxo de comunicação e interação entre os sujeitos presentes nesse espaço; - fluxo de interação entre os sujeitos e o meio, ou seja, o próprio espaço tecnológico.

A constituição de um ECODI, no contexto da educação, ocorre por meio das seguintes condições: ação e interação entre os participantes, a fim de configurar o espaço comum de forma colaborativa e cooperativa, por meio do viver e do conviver; inovações nos processos de ensino e de aprendizagem, por meio de práticas pedagógicas problematizadoras e em congruência com as TD.

Metodologia da Pesquisa

A metodologia utilizada é o estudo de caso, que implicou no desenvolvimento de três cursos de formação de professores em universidades brasileiras e francesas. Em cada estudo de caso foram definidos: os participantes da pesquisa (estudantes - educadores em formação), os espaços digitais virtuais (hibridismo tecnológico digital) e a prática pedagógica para potencializar os processos de interação e a ação dos participantes nos espaços digitais virtuais. Assim, constituímos os dados empíricos, coletados no desenvolvimento do curso de formação e definimos a forma de análise numa perspectiva complementar e de coexistência, fundamentada no quadro teórico proposto. Foram oferecidos três cursos de formação com encontros em espaço geograficamente localizado (sala de aula) e em espaços digitais virtuais (TD)

Caso 1 - Atividade complementar: Aprendizagem em Mundos Virtuais (2005). Formação destinada aos estudantes dos cursos de graduação em licenciatura da Universidade do Vale do Rio dos Sinos (Brasil). A formação iniciou com nove estudantes, mas se efetivou com um grupo de 
cinco participantes dos cursos de Pedagogia, Filosofia e Letras. A proposta se desenvolveu por meio da metodologia de Projetos de Aprendizagem baseada em Problemas, a partir da criação da Comunidade Virtual de Aprendizagem no AVA-UNISINOS e da construção de uma Vila localizada no MDV3D denominado de AWSINOS.

Caso 2 - Atividade complementar: Prática Pedagógica em Mundos Virtuais (2006). Formação também desenvolvida no Brasil constitui-se em um espaço de construção e efetivação de práticas pedagógicas utilizando - AWSINOS, perpassado por situações de reflexão sobre o processo de aprender e de ensinar. A proposta pedagógica foi construída a partir da solicitação dos estudantes, dando continuidade aos Projetos de Aprendizagens baseados em Problemas da atividade complementar anterior (realizada em 2005). A atividade complementar constitui-se de um grupo de seis participantes dos cursos de licenciatura em Pedagogia, Filosofia, Letras e do Curso de línguas.

Caso 3 - Travail Dirigé Analyse du travail et polyvalence. Formação do programa do Master (M1) Métiers de l'enseignement, de la formation, de la culture, ofertado pela Université Lumière Lyon 2. A proposta pedagógica desenvolvida se efetivou por meio da Metodologia Pedagógica inspirada no Estudo de Caso. Participou dessa formação um total de 19 estudantes, com uma desistência por motivo de transferência.

As formações propostas, nos contextos Brasil e França, tiveram início com a representação metafórica da Alegoria da Caverna de Platão (GAARDER, 1995), modelada no MDV3D denominado de AWSINOS (criado e construído no metaverso Active Worlds - versão educacional https://www.activeworlds.com/ index.html), conforme a Figura 1. A metáfora foi um convite aos educadores em formação, a saírem da caverna e conhecer outros mundos, de diferentes naturezas e na perspectiva da coexistência. Esse espaço digital virtual foi utilizado para as representações gráficas dos conhecimentos construídos, e as interações via chat (textual e gestual) entre os participantes, por meio do avatar, que pode ser visualizado na Figura 1. 


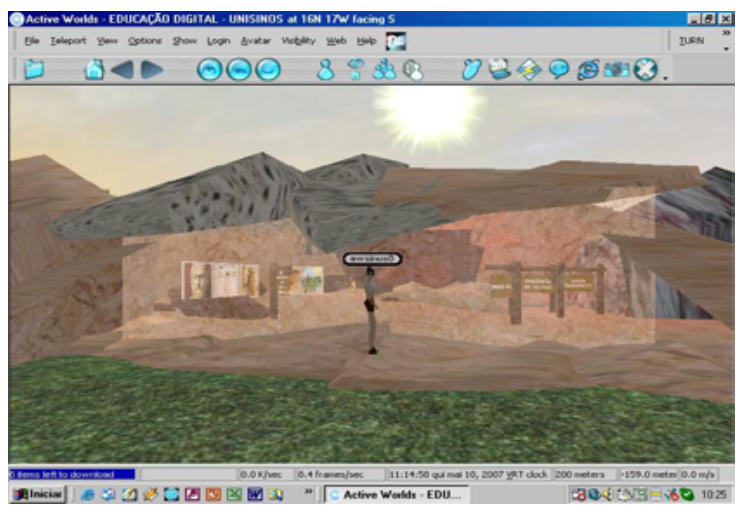

Figura 1 - Interface da Caverna no AWSINOS

Também foi utilizado o AVA-UNISINOS (o ambiente está descontinuado) no contexto Brasil, Figura 2. O espaço digital virtual foi utilizado para representação textual, por meio de seus recursos como: fórum, mural, chat, diário, glossário, autoavaliação e compartilhamento de arquivos eletrônicos. Esse ambiente foi concebido para propiciar a formação de comunidades virtuais de aprendizagem.

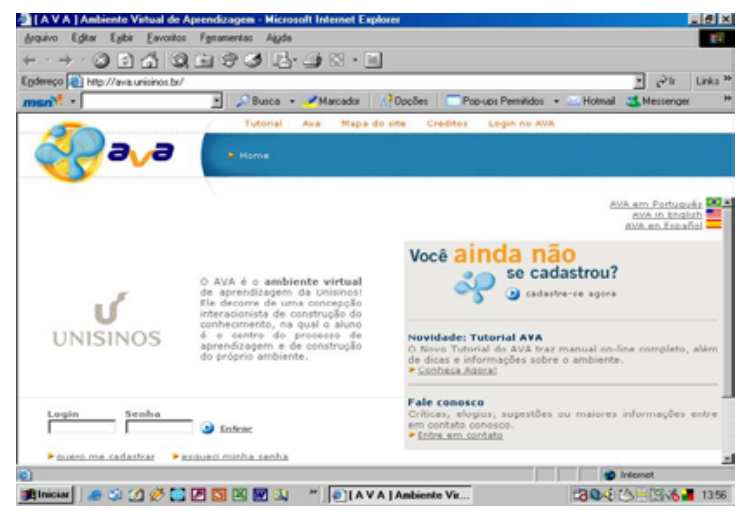

Figura 2 - Interface do AVA-UNISINOS

Na medida em que os participantes configuraram os espaços digitais virtuais de convivência, por meio das TD propostas na formação, os mesmos 
integraram a TD: comunicador instantâneo. Esse espaço digital virtual foi utilizado para comunicação via chat nos horários extra-atividade. O comunicador instantâneo utilizado foi o Messenger (atualmente movido para o Skype).

No contexto da França, foi utilizado o blog "Analyse du travail et Polyvalence" (acesso restrito), Figura 3, para os registros textuais, realizados de três formas diferentes: fóruns propostos para discutir os casos estudados; comentários solicitados a respeito das aprendizagens ocorridas, a cada encontro; autoavaliação.

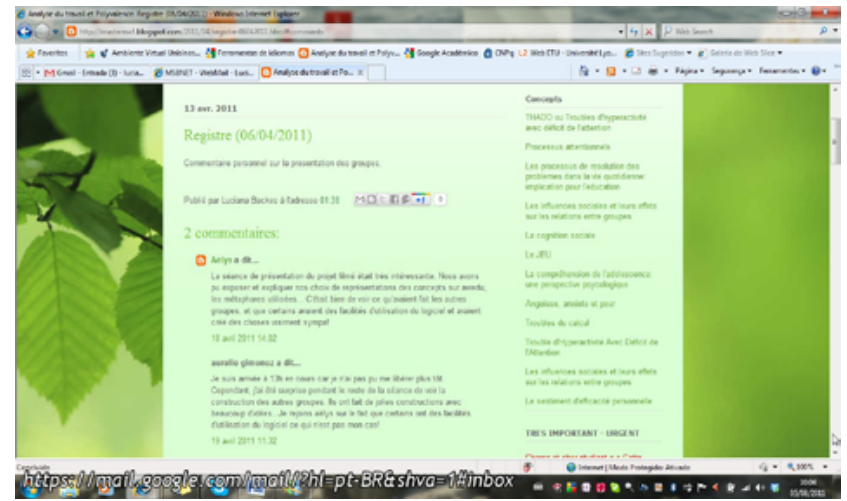

Figura 3 - Interface do blog

Na medida em que os participantes, do contexto França, foram configurando os espaços digitais virtuais de convivência, por meio das TD propostas na formação, os mesmos integraram a TD: mídia social (Facebook - https://www.facebook.com/). Esse espaço digital virtual foi utilizado para comunicação nos horários extra-atividade, identificado nos registros encontrados no blog e no chat realizado no AWSINOS.

As diferentes TD utilizadas no processo de formação podem ser consideradas espaços digitais virtuais, no que diz respeito à possibilidade de ação, representação e interação dos participantes. As mesmas são utilizadas de forma conjunta e articuladas, por meio de links que possibilitam a mobilidade entre as TD. Nesse hibridismo, os participantes tinham a impressão de utilizar uma única tecnologia, integrada e articulada. Dessa forma, criamos e recriamos o contexto do hibridismo tecnológico digital. 
O contexto do hibridismo tecnológico digital, nos processos de formação, dos contextos Brasil e França, se construiu na ação e na interação dos participantes, por meio das seguintes interfaces:

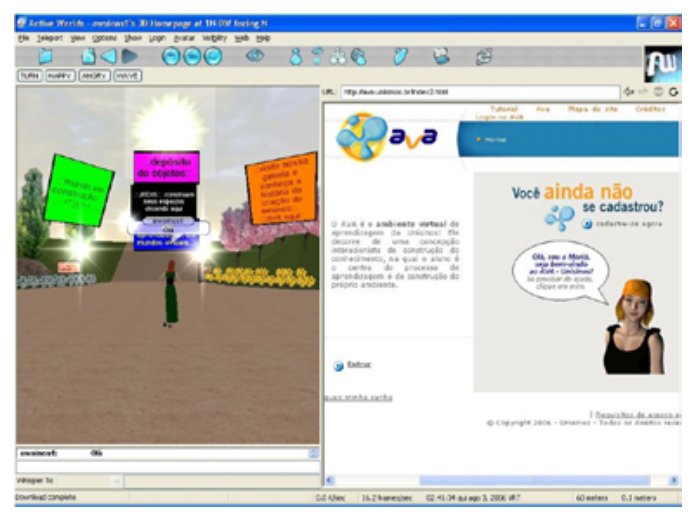

Figura 4 - AWSINOS e o AVA-UNISINOS

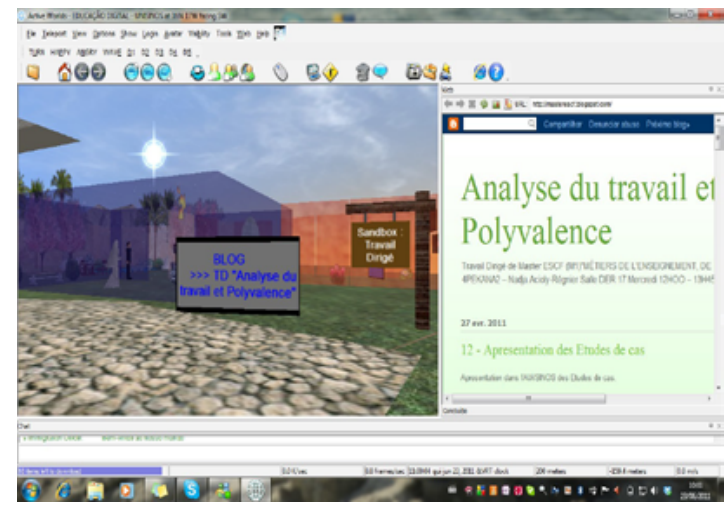

Figura 5 - AWSINOS e o blog «Analyse du travail et Polyvalence»

Na Figura 4 visualizamos o hibridismo tecnológico digital referente à formação desenvolvida no Brasil e na Figura 5 referente à formação desenvolvida na França.

No contexto do hibridismo tecnológico digital, configurado por cada grupo de maneira própria e particular, o AWSINOS foi utilizado nos três 
processos formativos. Assim, estudantes brasileiros e franceses construíram no mesmo MDV3D (AWSINOS), mas em momentos diferentes.

\section{REFLEXÕES SOBRE AS ANÁLISES DOS DADOS EMPÍRICOS}

Os dados empíricos coletados resultaram das representações dos processos de interação entre os estudantes (educadores em formação) por meio das diferentes espaços digitais virtuais (TD), assim como as representações do espaço geograficamente localizado (sala de aula), portanto a análise é de natureza qualitativa. Nesse artigo, são analisados alguns exemplos de configuração de espaço de convivência evidenciados nas diferentes formações desenvolvidas para a pesquisa.

Os dados foram analisados de maneira complexa, ou seja, foram estabelecidas relações, articulações, comparações, a fim de refletir sobre como ocorre a configuração do espaço digital virtual de convivência em relação à formação do educador. Em alguns momentos será abordado o contexto Brasil e em outros será abordado o contexto França, no entanto, em muitos momentos, os contextos Brasil e França estão relacionados e são complementares quando pensamos em espaços digitais virtuais.

Na reflexão sobre a configuração dos espaços digitais virtuais de convivência, foram mobilizadas, inicialmente, as seguintes unidades de análise: Autonomia individual; Autopoiese; Autoria transformadora, conforme Backes (2007, 2011, 2014). Essas unidades de análise foram mobilizadas porque se acredita que estão diretamente relacionadas à configuração do espaço digital de convivência. As unidades são caracterizadas da seguinte forma:

Tabela 1 - Caracterização das unidades de análise

\begin{tabular}{ll}
\hline Unidades de análise & Características \\
\hline Autonomia individual & $\begin{array}{l}\text { Ação do ser humano } \\
\text { Identificação do que lhe é significativo } \\
\text { Construção de regras para as suas açães }\end{array}$ \\
Autopoiese & $\begin{array}{l}\text { Ação do ser humano e reflexão } \\
\text { Autoprodução da ação (fazer) } \\
\text { Autoprodução do conhecimento (compreender) }\end{array}$
\end{tabular}


As unidades de análise contribuem para a reflexão sobre a seguinte questão: Como pensar a configuração dos espaços digitais virtuais de convivência, nos processos de ensinar e de aprender, na formação dos educadores, no contexto do hibridismo tecnológico digital?

\section{CONFIGURAÇÃO DO ESPAÇO DIGITAL VIRTUAL DE CONVIVÊNCIA}

A configuração do espaço digital virtual de convivência é uma compreensão do espaço de convivência (MATURANA;VARELA, 2002), configurada em espaços digitais virtuais. Conforme Maturana e Varela (2002, apud Backes, 2011) a configuração dos espaços de convivência ocorre no fluxo de interações entre os seres humanos e entre os seres humanos e o meio, o que possibilita a transformação dos seres humanos e do meio de maneira recursiva, no viver e conviver cotidiano. Nessa configuração há o entrelaçamento das emoções, das percepções, das representações, das perturbações, das compensações e das perturbações.

Portanto, a configuração da convivência implica na representação de cada ser humano em processo de interação em que construímos a representação do grupo, entendendo a coexistência dos seres humanos na construção da nova dimensão. O grupo, na configuração da convivência, constitui as condutas adequadas. "A conduta adequada é a conduta que é congruente com as circunstâncias nas quais ela se realiza" (MATURANA, 2002, p. 62).

Então a reflexão sobre a configuração dos espaços digitais virtuais de convivência ocorreu em espaços digitais virtuais (TD), no contexto do hibridismo tecnológico digital. Tanto no contexto Brasil como no contexto França foram utilizadas pelos estudantes as TD propostas no programa da formação, assim como as TD que os estudantes inseriram. No contexto Brasil, os participantes começaram a utilizar um comunicador instantâneo e no contexto França, os participantes utilizaram uma mídia social. A par- 
tir dessa evidência, retomamos Leroi-Gourhan (apud SANTOS, 2006) ao tratar da hipótese da universalidade da técnica, pois os objetos e a forma de utilizá-los não se restringem ao lugar da criação e evidenciamos que quando tratamos de espaços digitais virtuais, a universalidade da técnica é potencializada. Também podemos observar que os estudantes inseriram no processo formativo as TD que fazem parte do seu conviver cotidiano, de maneira natural e espontânea.

A configuração do espaço digital virtual de convivência ocorre na representação da percepção de cada ser humano, ou seja, na definição do espaço de cada um em relação ao grupo que pertence. Desta forma é possível instaurar a perturbação e/ou estranhamento, iniciando o processo de interação e a ação de superação da perturbação.

A articulação entre as unidades de análise pode ser evidenciada na discussão sobre o Estudo de Caso 1, proposto aos participantes da França. $O$ estudo de Caso 1 relata duas situações diferentes, numa mesma escola, com estudantes de uma mesma família, de origem africana. Na primeira situação é relatada a dificuldade de aprendizagem do irmão mais velho e as estratégias discriminatórias utilizadas pelo educador para compensar a dificuldade. Na segunda situação é relatada a repreensão exagerada à irmã mais nova, por parte do educador, quando ela utiliza os sapatos da sua mãe, durante a aula de educação física. Na representação do participante Ind071' Quadro 1, evidenciamos: a identificação de situações significativas no seu contexto; interpretação da ação do educador (observado) como racista e preconceituosa, atribuindo o seu significado, autonomia individual.

Quadro 1 - Fórum Estudo de Caso 1 (França)

Ind07 - Eu tenho a impressão de que esses dois alunos, os africanos, foram vistos num ângulo negativo por causa da sua origem, e, portanto, o comportamento dos professores pode ser classificado como: Agressão gratuita para a irmã mais nova e desdém para o irmão mais velho. Então, para mim, é um comportamento racista, mesmo que "inconsciente". (tradução livre da autora)

Fonte: Extraído pela autora do blog "Analyse du travail et Polyvalence"

Após o comentário do Ind07, os demais colegas manifestaram suas percepções, numa relação não hierárquica sem esperar uma manifestação

1 Educadores em formação, participantes da pesquisa. 
do educador, o que não é evidente para os estudantes. Também é possível observar a legitimidade do outro, ao considerar a representação do Ind07 como ponto de partida do processo de interação, fluxo fundamental para a configuração do espaço digital virtual de convivência.

O Ind04 registra no mesmo fórum, Quadro 2, sua percepção sobre o estudo de Caso 1, alterando o ponto de vista inicial da situação relatada.

Quadro 2 - Fórum Estudo de Caso 1 (França)

Ind04 - Sobre a segunda situação, é possível que tu estás sendo um pouco subjetiva. Portanto, sem dizer que a tua análise é falsa, porque nada justifica ou possa justificar uma discriminação, mas talvez o professor reaja dessa maneira com qualquer outro estudante, mesmo com outro estudante de origem francesa. Mas é preciso encontrar uma solução, compreender o porquê, pois ele já havia dito que não era permitido usar sapatos de pessoas adultas, ela refez a ação. [...] Sobre essa segunda situação, acredito que a reação do professor foi inadequada e desproporcional. Talvez sua intenção tenha sido de proteger a criança ao proibir de jogar futebol, mas ele se mostrou severo e irônico (foi fácil para ele). (tradução livre da autora)

Fonte: Extraído pela autora do blog "Analyse du travail et Polyvalence"

O Ind04 altera a lógica em relação ao caso: mobiliza outros conceitos relacionados à educação como: disciplina e limite; realiza articulações: o cuidado em relação à infância; propõe a construção de novos conhecimentos: perturbação em relação à discriminação e ao preconceito, evidência inadequada da postura profissional. O Ind04, ao representar sua percepção por meio da autoria transformadora, instaura outras perturbações ao grupo. No Quadro 3, o Ind07 busca compensar: coloca-se na posição do educador (observado); por meio da autopoiese transforma sua visão inicial; propõe novas perturbações. Nesse caso é importante ressaltar que o Ind07 não tomou a representação do Ind04 como sua, mas a ressignificou a partir da perturbação, do contexto e da sua ontogenia, ou seja, em congruência com o espaço.

\section{Quadro 3 - Fórum Estudo de Caso 1 (França)}

Ind07 - Após a leitura desse comentário, eu me pergunto: O que faríamos nessa situação como professor? É verdade o que disse o Ind04, nós podemos prever algumas posturas em relação a determinadas situações, mas quando ocorre nem sempre estamos preparados. Mas nessa situação, será que é a única solução? É uma solução eficaz, considerando que a estudante já tem dificuldade em acompanhar sua classe (CM2)? Talvez a estudante possa acompanhar melhor e integrar sua classe se são propostas verdadeiras soluções, como acompanhamento da equipe pedagógica? O que tu farias nessa situação? (tradução livre da autora)

Fonte: Extraído pela autora do blog "Analyse du travail et Polyvalence" 
Em interação, o Ind01 amplia as perturbações propostas no estudo de Caso 1, Quadro 4, e inicia a compensação por meio da autonomia individual. Assim, o Ind01: contempla as percepções abordadas pelos colegas (legitimidade do outro); constrói uma nova hipótese sobre o caso (autopoiese).

Quadro 4 - Fórum Estudo de Caso 1 (França)

Ind01 - Da minha parte, eu também penso que o professor "fez mal o seu trabalho" com a estudante. Ele deveria procurar soluções para integrar e compensar as dificuldades. De um outro lado eu não sei quais foram as ações que ele já propôs antes dessa situação. Talvez ele tenha a impressão de ter feito tudo que era possível, todo o esforço por nada e ele abandonou. (tradução livre da autora)

Fonte: Extraído pela autora do blog "Analyse du travail et Polyvalence"

Nessa situação evidenciamos a configuração do espaço digital virtual de convivência de maneira recursiva entre os seres humanos (estudante) e o espaço (TD). Os estudantes ampliaram o fluxo de interação, avançaram na construção do conhecimento que implicava o estudo de caso, deram dinâmica ao blog, ampliaram as informações no blog, utilizaram essas informações para a construção no AWSINOS da "Maison Multiculturelle", Figura 6, e tudo isso no cotidiano de todo o dia.

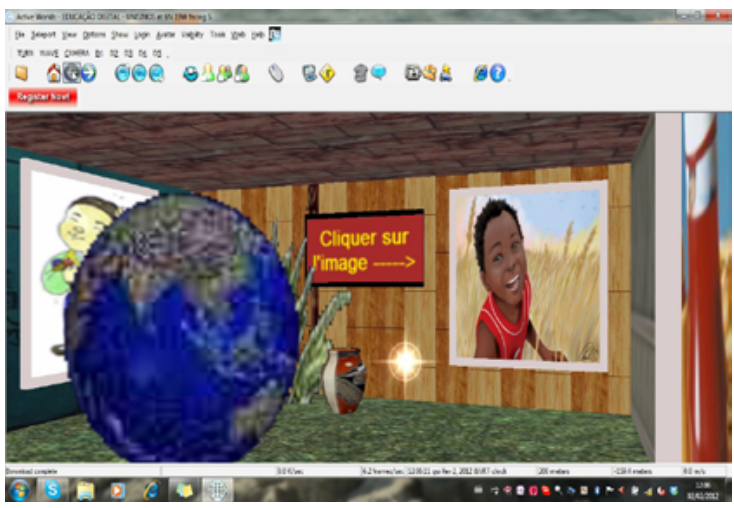

Figura 6 - Representação metafórica Maison Multiculturelle no AWSINOS

No chat 2, Quadro 5, realizado durante a construção metafórica da teoria Interacionista no AWSINOS, contexto Brasil, evidenciamos o processo de interação, em que são discutidos aspectos epistemológicos e aspectos técnicos, a seguinte configuração do espaço digital virtual: 
Quadro 5 - Chat 2 (Brasil)

Ind07: tá muito bonito

Ind06: é, mas passei a semana construindo e desconstruindo

Ind06: ou melhor eu mais desconstrui

Ind07: é assim mesmo

Ind07: não sei o que acontece com esse chão...

Ind06: vc vê, se abaixa ele desaparece,

Ind06: a não ser que troque o chão, este gramado

Ind07: é bem estranho

Ind06: mas sua área é diferente, ou melhor o tamanho

Ind07: acho que precisamos pegar um objeto que está no mesmo nível e transformá-lo no chão, vou ver se consigo fazer isso com a grama

Fonte: Extraído pela autora do chat no AWSINOS

A configuração do espaço digital virtual de convivência se dá na configuração de um espaço comum: ambos os participantes estavam engajados na descoberta da solução para a construção do solo no AWSINOS, envolvendo conhecimentos técnicos; e de condutas adequadas: para construir, foi necessário desconstruir, envolvendo aspectos também epistemológicos.

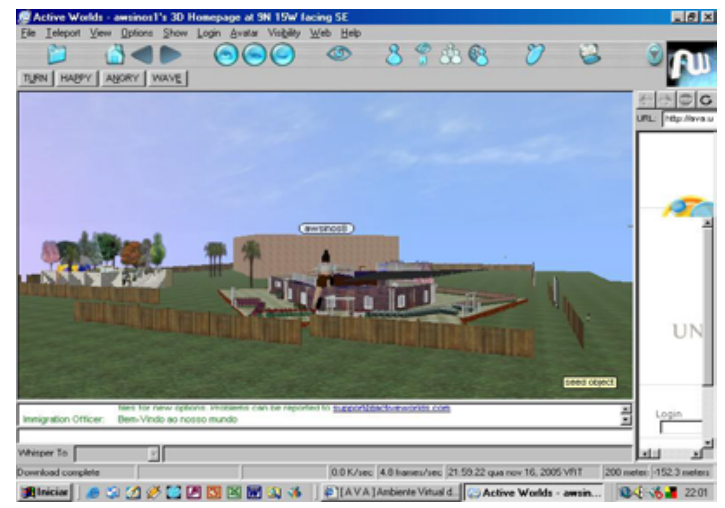

Figura 7 - Representação metafórica construída no momento do Chat 2

Portanto, evidenciamos também a configuração do espaço digital de convivência de maneira recursiva entre os seres humanos e o espaço. Nesse sentido há transformação dos seres humanos e dos espaços de maneira congruente. 
No fluxo de interação, realizado no chat para construção do AWSINOS no contexto França, Quadro 6, evidenciamos a perturbação do Ind19, representada aos colegas que, numa relação não hierárquica, tentam compensar. A perturbação do Ind19 é legitimada pelo grupo.

Quadro 6 - Chat (França)

Ind19: Achei interessante o que tu fizeste!!! Mas eu ainda não entendo o Active Worlds, além de achar muito complicado o que tu disseste sobre a representação metafórica dos conceitos!!

Ind05: Eu sei

Ind19: Como fizemos para ir na nossa construção!!!

Ind05: Bem, os conceitos teóricos ainda não foram construídos.

[...]

Ind05: Siga a estrada

Ind14: Onde tu estás Ind05?

Ind09: Bem ao fundo, à direita

Ind01: Tu vês o Ind09, tem um problema com a parede

Ind05: Eu estou sobre o telhado. (tradução livre da autora)

Fonte: Extraído pela autora do chat no AWSINOS

Na interação evidenciamos: a perturbação em relação à construção do AWSINOS para representar metaforicamente os conhecimentos mobilizados nos casos estudados; a relação não hierárquica, os participantes procuram alternativas no coletivo para superar a dificuldade sem esperar a intervenção do educador; a legitimidade do outro, orientando o Ind19 na localização no AWSINOS e para que compreenda as representações construídas. Nesse caso, todos estão envolvidos na construção do AWSINOS, sobretudo quando há dificuldade, tornando essa, uma conduta adequada na configuração do espaço digital virtual de convivência. Salientamos o quanto é difícil para estudantes e educadores proporem práticas pedagógicas diferenciadas.

Dessa forma, evidenciamos que o espaço digital virtual de convivência se configura quando: os seres humanos representam a sua percepção, seja de maneira textual, oral, gestual, gráfica ou metafórica, em espaços digitais virtuais (autonomia individual); a partir da representação que cada ser humano instaura a perturbação e configura um espaço comum, na perspectiva de superação e de emergência (autopoiese e autoria transformadora). Além 
dessas unidades de análise também observamos que para a compensação da perturbação há a necessidade de relações não hierárquicas e legitimação do outro.

\section{CONCLUSÃo}

Nos espaços digitais virtuais de convivência, os seres humanos representam as suas compreensões e definições, assim, designando o espaço de cada um. No fluxo interação, no viver e conviver cotidiano, os seres humanos instauram as perturbações e os estranhamentos, por meio de relações não hierárquicas. Ao legitimar a perturbação uns dos outros, os seres humanos, em grupo, desenvolvem as condutas adequadas para compensar a perturbação, configurando o que é comum, em congruência com o meio (contexto do hibridismo tecnológico digita). Dessa forma, na perspectiva da coexistência, os seres humanos são autores e coautores na construção de novos conhecimentos.

No contexto educacional, principalmente na formação de educadores, é importante o desenvolvimento de práticas pedagógicas problematizadoras (perturbação). Assim, os espaços digitais virtuais de convivência se efetivam na compensação do problema (perturbação), na legitimidade do outro e na relação não hierárquica entre seres humanos que são coensinantes e coaprendentes.

As práticas pedagógicas, enquanto ação de educadores e estudantes, podem potencializar a configuração de espaços digitais virtuais de convivência, no contexto do hibridismo tecnológico digital, quando: educadores permitem aos estudantes manifestarem suas perturbações e estudantes se autorizam a problematizar aspectos que emergem do fluxo de interações durante o processo de informação; educadores e estudantes representam os conhecimentos metaforicamente, por meio de desenhos; estudantes utilizam TD que não foram propostas pelo educador, mas que fazem parte do cotidiano, invertendo a lógica que estamos habituados no contexto educativo. Portanto, este é um desafio que se faz com a participação de todos. 


\section{EL HIBRIDISMO TECNOLÓGICO DIGITAL EN LA CONFIGURACIÓN DEL ESPACIO DIGITAL VIRTUAL DE CONVIVENCIA: FORMACIÓN DEL EDUCADOR}

El artículo aborda la formación del educador a través de las tecnologías digitales emergentes. La investigación abarca dos aspectos: contexto del hibridismo tecnológico digital; configuración de los espacios digitales virtuales de convivencia. La reflexión ocurrió en los cursos de formación inicial del educador, desarrollado en Brasil y Francia, en el contexto del hibridismo tecnológico digital compuesta por: Ambiente Virtual de Aprendizaje; Comunicador Instantáneo; Blog y Metaverso. A través de la metodología de estudio de caso, se observó que el espacio virtual digital de convivencia se configura cuando: los seres humanos representan su percepción en espacios virtuales digitales; a partir de la representación de cada ser humano se establece la perturbación, porque el otro es legítimo; hay una necesidad de compensar la perturbación configurando un espacio común, en la perspectiva de coexistencia y de emergencia.

Palabras clave: Espacio. Hibridismo tecnológico digital. Espacio virtual digital de convivencia. Formación del educador.

\section{THE HYBRIDITY DIGITAL TECHNOLOGY OF THE DIGITAL VIRTUAL SPACES OF COEXISTENCE: TEACHER EDUCATION}

ABSTRACT: The article discusses the formation of the educator through emerging digital technologies. The research focuses on two aspects: the context of digital technology hybridity and the configuration of virtual digital living spaces. The reflection occurred during the course of initial teacher education, developed in Brazil and France, in the context of digital technology hybrid composed of Virtual Learning Environment; Instant Communicator, Metaverse and Blog. Through the Case Study methodology we noted that the digital virtual living space is configured when: humans represent their perception in virtual digital spaces, from the representation of each human being the disturbance is introduced, for the other is right; there is the need to compensate the disturbance configuring a common space in a perspective of coexistence and emergency.

KeYwords: Space. Hybrid digital technology. Digital virtual space of coexistence. Teacher education. 


\section{NOTAS}

1) Uma versão preliminar deste trabalho foi apresentada no "III Colóquio Luso-Brasileiro de Educação a Distância e Elearning" em 2013 e publicada em seus anais sob o título "Hibridismo Tecnológico Digital: configuração dos espaços digitais virtuais de convivência".

\section{REFERÊNCIAS}

BACKES, L. Hibridismo Tecnológico Digital: configuração dos espaços digitais virtuais de convivência. III Colóquio Luso-Brasileiro de Educação a Distância e Elearning, Lisboa: Editora Universidade Aberta, v. 1, p. 1-18, 2013.

. Espaço de Convivência Digital Virtual (ECODI): O acoplamento estrutural no processo de interação. ETD Educação Temática Digital, v. 15, p. 337-355, 2013.

Práticas Pedagógicas na Formação do Educador por meio do Hibridismo Tecnológico Digital: Contexto Brasil e França. Atas VII Congresso Iberoamericano de Docência Universitária, Porto, n. 1, p. 1886-1903, 2012.

. A Configuração do Espaço de Convivência Digital Virtual: A cultura emergente no processo de formação do educador. Tese (Doutorado em Educação) - Programa de Pós-Graduação em Educação, Universidade do Vale do Rio dos Sinos, São Leopoldo-RS, (co-tutela Science de I'Education), Université Lumière Lyon 2, Lyon, FR, 2011.

A Formação do Educador em Mundos Virtuais: Uma investigação sobre os processos de autonomia e de autoria. Dissertação (Mestrado em Educação) - Programa de Pós-Graduação em Educação, Universidade do Vale do Rio dos Sinos, São Leopoldo-RS, 2007.

CANCLINI, N. G. Culturas híbridas. São Paulo: Edusp, 2006.

GAARDER, J. O Mundo de Sofia: Romance da história da filosofia. São Paulo: Companhia das Letras, 1995.

FRANK, C. O. Aprendizagem da língua espanhola por meio das tecnologias digitais. Dissertação (Mestrado em Educação) - Centro Universitário La Salle, Canoas-RS, 2012.

LATOUR, B. Nous n'avons jamais été modernes, essai d'anthropologie symétrique. Paris: La Découverte, 1991.

LEMOS, A. Cibercultura, tecnologia e vida social na cultura contemporânea. Porto Alegre: Sulina, 2007.

LEVY, P. Cibercultura. Rio de Janeiro: Editora 34, 2010.

MATURANA, H. R.; REZEPKA, S. N. Formação humana e capacitação. Petrópolis (RJ): Vozes, 2008. 
.; VARELA, F. J. A árvore do conhecimento: As bases biológicas da compreensão humana. São Paulo: Palas Athena, 2002.

. A ontologia da realidade. Belo Horizonte: Ed. UFMG, 2002.

MORIN, E. Introdução ao Pensamento Complexo. Porto Alegre: Sulina, 2011.

SANTOS, M. Por uma Geografia Nova: Da crítica da geografia a uma geografia crítica. São Paulo: Editora HUCITEC, 1980.

A Natureza do Espaço: Técnica e Tempo, Razão e Emoção. São Paulo: Editora da Universidade de São Paulo, 2006.

SCHLEMMER, E. Dos Ambientes Virtuais de Aprendizagem aos Espaços de Convivência Digitais Virtuais - ECODIS: O que se mantêm? O que se modificou? In: VALENTI, C. B.; SACRAMENTO, E. M. (Org.). Aprendizagem em ambientes virtuais [recurso eletrônico]: compartilhando ideias e construindo cenários. Caxias do Sul (RS): Educs, 2010, p. 145-191.

. Telepresença. Curitiba: IESDE Brasil S. A., 2009.

. ECODI - A criação de espaços de convivência digital virtual no contexto dos processos de ensino e aprendizagem em metaverso. Cadernos IHU Ideias (UNISINOS), v.6, p. 1-32, 2008.

. AVA: um ambiente de convivência interacionista construtivista sistêmico para comunidades virtuais na cultura da aprendizagem. Tese (Doutorado em Informática na Educação) - Universidade Federal do Rio Grande do Sul, Porto Alegre-RS, 2002.

Projetos de aprendizagem baseados em problemas: uma metodologia interacionista/construtivista para formação de comunidades em Ambientes Virtuais de Aprendizagem.Colabor@ (Curitiba),Curitiba, v. 1, n. 2, p. 1-10, 2001.

; BACKES, L.; FRANK, P. S. S.; SILVA, F. A.; SENT, D. T. (2006). ECoDI: A criação de um Espaço de Convivências Digital Virtual. Atas XVII Simpósio Brasileiro de Informática na Educação - XVII SBIE, Brasília, 2006.

LUCIANA BACKES: Doutora em Educação pela Universidade do Vale do Rio dos Sinos (Unisinos) e Sciences de l'Education pela Université Lumière Lyon 2. Bolsa de Estágio Pós-Doutoral no Exterior CAPES, na I'Université Paris Descartes Paris V - Sorbonne. Professora titular do Centro Universitário LaSalle (Unilasalle), Programa de Pós- Graduação em Educação. Tem experiência na área de Educação, com ênfase em Educação Digital, atuando principalmente nos seguintes temas: processos de ensino e de aprendizagem, construção do conhecimento, formação do educador, práticas pedagógicas, informática na educação. E-mail: lucianabackes@gmail.com 